Original Research Paper

\title{
Perencanaan Kawasan Wisata Edukasi Mangrove Tanjung Batu, Sekotong Tengah
}

\author{
Kornelia Webliana B ${ }^{1}$, Andi Chairil Ichsan ${ }^{1}$, Irwan Mahakam Lesmono Aji ${ }^{1}$, Maiser Syaputra ${ }^{1}$, Diah \\ Permata Sari $^{1}$, Wihelmus Jemarut ${ }^{6}$ \\ ${ }^{1}$ Program Studi Kehutanan, Fakultas Pertanian, Universitas Mataram, NTB, Indonesia \\ ${ }^{2}$ Institut Agama Hindu Negeri Gde Pudja Mataram, NTB, Indonesia
}

https://doi.org/10.29303/jpmpi.v3i2.1216

Sitasi: Weblina B, K., Ichsan, A. C., Aji, I. M. L., Syaputra, M., Sari, D. P \& Jemarut, W. (2021). Perencanaan Kawasan Wisata Edukasi Mangrove Tanjung Batu, Sekotong Tengah. Jurnal Pengabdian Magister Pendidikan IPA, $5(1)$

\section{Article history}

Received: 20 November 2021 Revised: 30 Desember 2021

Accepted: 5 Januari 2022

*Corresponding Author:

Kornelia Webliana, Program

Studi Kehutanan Universitas

Mataram, Mataram, Indoneisa

Email:

$\underline{\text { Kornelia_webliana@unram.ac.id }}$

\begin{abstract}
The establishment of educational tourism in mangrove areas is expected to prevent and overcome the impact of tourist activities on nature and culture. This community service activity was carried out in the Tanjung Batu Mangrove area, Sekotong Village with the aim of designing an educational tourism concept to maximize the use of mangroves as a new tourist attraction in the Central Sekotong area. The selection of mangrove locations was carried out by purposive sampling, and the methods applied to this service were observation, socialization, discussion and direct area arrangement. The results of observations showed the potential flora in Tanjung Batu, namely Rhizophora mucronata, Rhizophora stylosa and Avicennia lanata. Meanwhile, the birds types found in this area are terns, swallows, black eagles, sparrows, king prawns and Asian plover. The potential of flora and fauna is then described in the Flora-Fauna interpretation board and a short documentary related to the area which was prepared jointly by the manager and the community service team. Recommendations for the types of educational tourism activities that can be offered for the Tanjung Batu Mangrove area, namely bird watching, mangrove planting, canoeing, and making mangrove films.
\end{abstract}

Keywords: Mangrove, Tanjung Batu, Educational tourism

\section{Pendahuluan}

Indonesia merupakan negara yang memiliki tingkat keanekaragaman hayati pesisir dan laut yang tinggi. Kekayaan alam dengan keanekaragaman hayati yang tinggi memiliki banyak manfaat yang penting dan strategis sebagai modal dasar pembangunan nasional serta dapat menjadi paru-paru dunia yang sangat penting bagi masa kini ataupun masa mendatang (Susilawati et al., 2008).

Ekosistem Mangrove adalah salah satu spesies kunci di wilayah pesisir yang memiliki nilai ekologi, lingkungan dan sosioekonomi. Menurut (Medrizam et al., 2004) nilai penting mangrove pada kawasan peisisir yaitu memelihara kualitas perairan pantai, mengurangi dampak kerusakan akibat badai, gelombang dan banjir pantai, areal pembesaran dan pencari pakan untuk perikanan komersil maupun trandisional, habitat penting dan areal pencari pakan untuk berbagai jenis satwa liar, dan penghasil produk kayu dan non kayu.

Lombok Barat merupakan wilayah di NTB yang memiliki kawasan Mangrove yang saat ini telah dikembangkan sebagai kawasan ekowisata. Salah satu kawasan di Lombok Barat yang 
memiliki potensi mangrove yang cukup menjadi perhatian adalah mangrove Tanjung Batu. Mangrove Tanjung Batu secara administratif masuk dalam Kawasan Ekosistem Esensial Koridor Mangrove Teluk Lembar, wilayah Desa Sekotong Tengah, Kecamatan Sekotong. Salah satu bentuk usaha yang dilakukan oleh pemerintah Desa Sekotong Tengah dalam rangka tetap menjaga eksistensi kawasan mangrove yang tersisa yaitu dengan cara pengelolaan kawasan mangrove menjadi salah satu atraksi wisata yang mengusung konsep Ekowisata. Pada dasarnya dalam pengembangan kawasan ekowisata salah satu aspek penting yang harus diperhatikan adalan Pendidikan konservasi yang diberikan kepada wisatawan. Konsep yang dapat dikembangkan yaitu dengan membentuk paket wisata edukasi yang diharapkan dapat mencegah dan menaggulangi dampak dari aktivitas wisatawan terhadap alam dan budaya (Fandeli, 2002). Wisata edukasi dapat diartikan sebagai sebuah gagasan yang menerapkan pendidikan non formal terhadap sebuah pengetahuan ketika berkunjung pada sebuah Kawasan wisata (Wijaya, 2020). Namun permasalahan yang terjadi adalah sampai dengan saat adalah belum maksimalnya penataan kawasan wisata mangrove untuk tujuan wisata edukasi. Oleh karena itu perlu dilakukan kegiatan pendampingan pada masyarakat untuk mendukung pengembangan wisata edukasi kawasan mangrove Tanjung Batu.

\section{METODE :}

Pengabdian dilaksanakan pada bulan SeptemberOktober 2021, berlokasi di kawasan Mangrove Tanjung Batu, Desa Sekotong Tengah Lombok Barat. Pemilihan lokasi dilakukan dengan metode Purposive Sampling dengan pertimbangan sebagai berikut:

a) Mangrove Tanjung Batu, Desa Sekotong Tengah merupakan salah satu kawasan Mangrove yang masuk dalam Kawasan ekosistem esesnsial koridor mangrove wilayah Lombok Barat yang saat ini mulai berkembang. b) Terdapat Kawasan wisata lain yang cukup terkenal di sekitar kawasan Mangrove Tanjung Batu sehingga dapat dijadikan sebagai satu kesatuan destinasi wisata.

Metode yang diterapkan pada pengabdian ini adalah observasi, sosialisasi, diskusi terkait penataan kawasan dalam upaya mewujudkan wisata edukasi di kawasan wisata Mangrove Tanjung Batu. Setelah dilakukan diskusi, tim pengelola dan tim pengabdian melakukan dan penataan kawasan secara langsung. Rincian kegiatan dapat dijabarkan sebagai berikut :

\section{a. Tahapan Observasi}

Melakukan pengamatan langsung di lapangan untuk mendapatkan data keanekaragaman hayati Flora dan Fauna di kawasan Mangrove Tanjung Batu.

\section{b. Tahapan Diskusi dan sosialisasi}

Hasil observasi di lapangan kemudian disosialisasikan pada pengelola kawasan dalam hal ini pemerintah Desa Sekotong Tengah dan POKDARWIS Tanjung Batu. Yang kemudian secara Bersama-sama merumuskan konsep wisata edukasi di kawasan ini.

\section{c. Tahap Penataan Kawasan}

Penataan kawasan dilakukan untuk mendukung wisata edukasi di kawasan Mangrove Tanjung Batu dengan membuat papan informasi terkait jenis vegetasi dan satwa burung pada kawasan mangrove dan pembuatan video edukasi mangrove.

\section{HASIL dan PEMBAHASA N}

Hasil kegiatan pengabdian dapat dikelompokan menjadi tiga yaitu tahap identifikasi Flora-Fauna, desain program interpretasi kawasan wisata dan Rekomendasi jenis kegiatan untuk wisata edukasi. Tahapan tersebut dapat digambarkan sebagai berikut :

\section{A. Tahapan identifikasi Flora-Fauna di Kawasan Mangrove Tanjung Batu}

Ekowisata dapat diartikan sebgai kegiatan yang bertumpu pada lingkungan yang dapat 
mendatangkan manfaat ekologi, sosial dan ekonomi bagi masyarakat sekitar. Salah satu unsur penting dalam dalam pengembangan ekowisata adalah keaslian lingkungan alam dan budaya. Oleh karena itu untuk mendukung aspek lingkungan tersebut perlu dilakukan identifikasi florafauna di sekitar kawasan dengan tujuan untuk mengetahui kekayaan alam yang dimiliki oleh kawasan hutan mangrove tanjung batu, sehingga dalam perencanaan pengembangan kawasan ke depannya pengelola akan mempertimbangkan aspek lingkungan seperti daya dukung kawasan, aktivitas wisatawan dan juga aspek ekologis lainnya. Hasil identifikasi florafauna dapat digambarkan pada table berikut ini :

Tabel 1. Jenis Flora-Fauna yang ada di Kawasan Mangrove Tanjung Batu

\begin{tabular}{|l|l|c|}
\hline $\begin{array}{l}\text { Flora- } \\
\text { Fauna }\end{array}$ & Jenis & Keterangan \\
\hline Flora & $\begin{array}{l}\text { Rhizophora } \\
\text { mucronate } \\
\text { Rhizophora } \\
\text { stylosa }\end{array}$ & $\begin{array}{l}\text { Mendominasi } \\
\text { tingkat pohon } \\
\text { Mendominasi } \\
\text { tingkat pohon }\end{array}$ \\
& Avicennia lanata & $\begin{array}{l}\text { Mendominasi } \\
\text { tingkat semai, } \\
\text { sapihan serta } \\
\text { tiang/pancang }\end{array}$ \\
\hline $\begin{array}{l}\text { Fauna } \\
\text { (Jenis } \\
\text { Burung) }\end{array}$ & Wara Laut & 62 ekor \\
& Elang Hitam & 62 ekor \\
& Burung Gereja, & 32 ekor \\
& Raja Udang & 24 ekor \\
Cerek Asia. & 21 ekor \\
\hline
\end{tabular}

Sumber : Data Primer, 2021

Hasil pengamatan di lapangan menunjukan terdapat tiga jenis mangrove pada kawasan ini yaitu Rhizophora mucronate, Rhizophora stylosa dan Avicennia lanata pada kategori pohon, semai dan tiang/pancang. Penentuan kategori semai, pancang pada kegiatan observasi mengacu pada (Direktur Jenderal Planologi Kehutanan dan Tata Lingkungan, 2017) yang mengkategorikan tingkat semai yaitu permudaan pohon dengan tinggi $<1,5$ $\mathrm{m}$, tingkat pancang yaitu permudaan pohon dengan tinggi tinggi $\geq 1,5 \mathrm{~m}$ tetapi dbh (diameter at breast height) $<5 \mathrm{~cm}$, ukuran tiang adalah $\mathrm{dbh} \geq 5-10 \mathrm{~cm}$ dan untuk pengamatan pohon memiliki ukuran dbh $\geq$ $10 \mathrm{~cm}$.

Hasil analisis menunjukan indeks keragaman dari flora di kawasan ini masih tergolong rendah. Oleh karena itu diperlukan upaya pengkayaan jenis, yang dapat disatukan dalam konsep pengembangan wisata edukasi. Hasil identifikasi flora-fauna ini dapat dijadikan sebagai salah satu program interpretasi di kawasan Mangrove Tanjung Batu. Menurut (Fandeli \& Mukhlison, 2000) interpretasi adalah kegiatan untuk menggambarkan keadaan lingkungan baik itu flora, fauna, dan proses biotik serta abiotik yang terjadi di dalam kawasan wisata pada pengunjung. Interpretasi ini diharapkan dapat menambah informasi, dan menguguah pikiran dari pengunjung untuk mengetahui, menyadari mendidik dan menarik minat wisatawan untuk dapat melestarikan kawasan Mangrove Tanjung Batu.

\section{B. Program Interpretasi Kawasan Wisata}

(Fandeli \& Mukhlison, 2000) menyatakan bahwa untuk melakukan kegiatan interpretasi perlu dibentuk suatu panduan atau tuntunan yang disusun oleh enterpreter yang bertujuan untuk mengapresiasi suatu feomena alam yang penting kepada pengunjung, sehingga pengunjung memperoleh pengetahuan setelah kembali dari destinasi wisata mangrove.

Beberapa hal yang harus dipersiapkan dalam rangka menyusun program interpretasi adalah sebagai berikut : 
a. Menetapkan Point of interest.

b. Membuat jalur interpretasi

c. Memasang papan penunjuk/pemandu

d. Membuat Display

e. Fasilitas pendukung lainnya (pusat infromasi, slide dan film,pameran, dll)

Hasil diskusi dengan pengelola kawasan, dapat disimpulkan beberapa kegiatan yang dapat dilakukan dalam rangka penyusunan program interpretasi kawasan Mangrove Tanjung Batu adalah sebagai berikut :

1. Menetapkan Point of Interest

Point of interest pada kawasan ini tetap mengacu pada keunikan dan keindahan Mangrove Tanjung Batu yang dapat dinikmati oleh wisatawan secara langsung pada jalur trekking yang telah disediakan, dengan dilengkapi oleh fasilitas-fasilitas yang saat ini sudah disediakan oleh Pemerintah Desa bekerjasama dengan Pemerintah Pusat, Provinsi dan Kabupaten.

Alternatif atraksi lain yang dapat dikembangkan pada saat ini yaitu Bird Watching atau wisata pengamatan burung di sekitar kawasan mangrove.

2. Jalur Interpretasi

Secara umum jalur interpretasi berfungsi untuk mengarahkan pengunjung ke tempat-tempat yang memiliki daya tarik berupa tumbuhan, satwa dan atraksi lainnya. Pada saat ini terdapat fasilitas jalur trekking wisata yang telah dibangun oleh pemerintah Propinsi NTB bekerjasama degan pemerintah Desa yang memiliki Panjang $\pm 500 \mathrm{~m}$. Jalur interpretasi baru yang dapat didesain oleh pengelola yaitu di pesisir sungai yang berbatasan langsung dengan kawasan mangrove. Jalur ini direkomendasikan karena berdasarkan hasil obervasi menunjukan kawasan ini adalah tempat terbaik untuk melakukan bird watching.

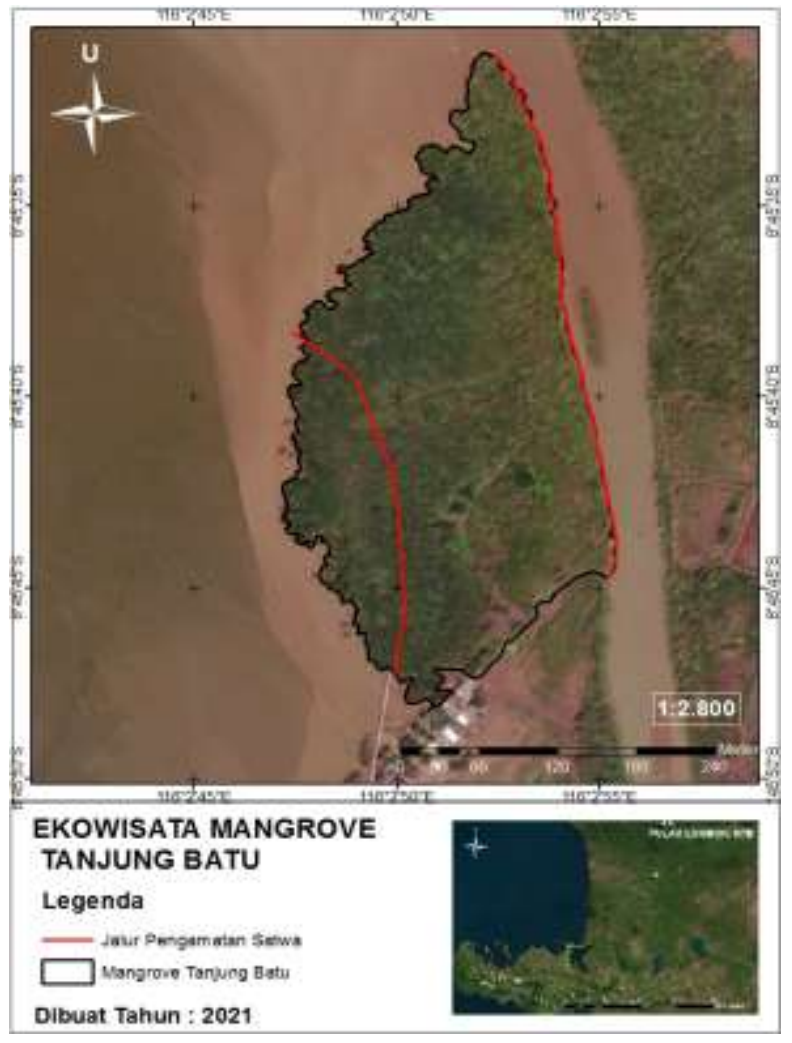

Gambar 1. Jalur pengamatan burung

3. Membuat Display

Kawasan wisata alam biasanya akan dilengkapi dengan bangunan pusat informasi yang bertujuan untuk memberikan gambaran mengenai apa saja yang dapat dilihat dan dipelajari pada kawasan (Fandeli \& Mukhlison, 2000). Pada kegiatan abdimas ini dilakukan kegiatan pemasangan papan informasi jenis flora dan fauna yang terdapat di Tanjung Batu, yang diharapkan dapat memberikan informasi, dan menambah pengetahuan wisatwan terkait kondisi keanekeragamanhayati kawasan mangrove. 


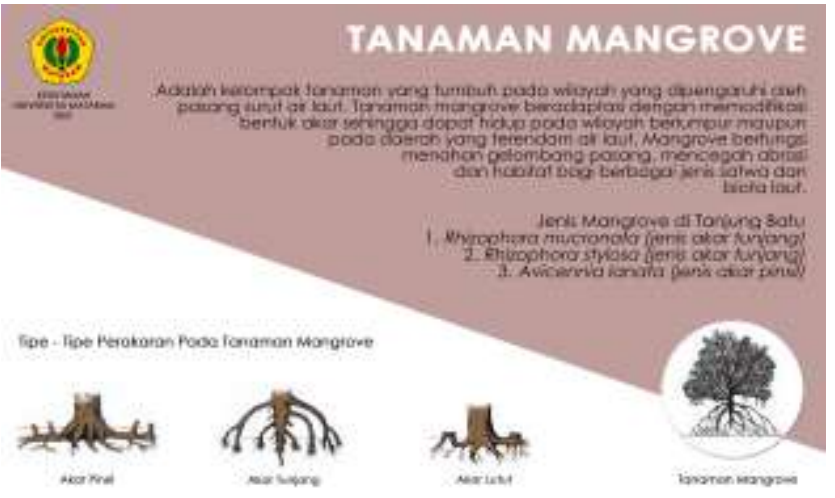

(a)

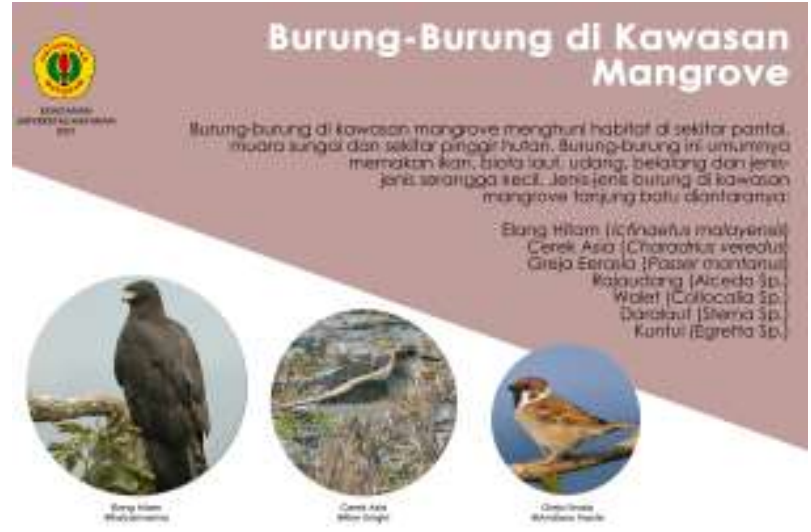

(b)

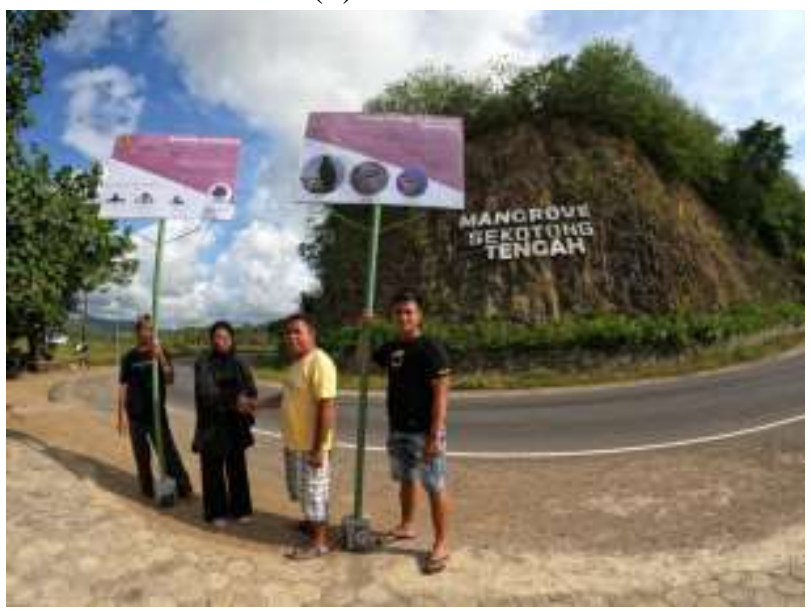

(c)

Gambar 2. Papan informasi mangrove dan satwa yang terdapat pada kawasan Tanjung Batu

\section{Fasilitas-fasilitas pendukung}

Fasilitas pendukung lain yang didesain pada saat kegiatan pengabdian yaitu video edukasi terkait mangrove yang dapat ditampilkan pada pusat informasi.
Video ini berisi profil singkat kawasan, pengenalan ekosistem mangrove (fungsi mangrove ditinjau dari ekologi, social, ekonomi), dan infromasi satwa yang dapat dijadikan sebagai atraksi pendukung di kawasan mangrove.

\section{Rekomendasi Aktifitas untuk Wisata Edukasi}

\section{Bird Watcthing}

Mengamati burung, atau birdwatching, adalah salah satu dari metode pendidikan konservasi yang membantu meningkatkan kesadaran akan pentingnya melindungi satwa liar burung di alam liar (Sukara et al., 2014). Aktivitas bird watching dapat dikembangkan di negara-negara tropis, dan pada saat ini bisnis birdwatching dianggap sebagai salah satu bisnis yang mampu memberikan keuntungan yang sangat besar (Welford \& Anthony Barilla, 2014). Kegiatan pengamatan burung merupakan objek rekreasi yang efektif karena perjalanan wisata menjadi lebih bermakna, berkualitas, dan memperkaya pengalaman serta pengetahuan terkait keragaman hayati di suatu tempat (Lakiu et al., 2016).

Setelah melakukan diskusi dengan pengelola kawasan, tim abdimas merekomendasikan bird watching sebagai salah satu atraksi utama yang dapat dikembangan pada kawasan Mangrove Tanjung Batu.

\section{Penanaman bibit mangrove}

Atraksi wisata edukasi lain yang direkomendasikan untuk dikembangkan di kawasan Mangrove Tanjung Batu adalah living class mangrove dan penanaman bibit mangrove. Lokasi penanaman bibit mangrove berada di pinggir jalan dekat dengan jalur trekking dan pintu masuk kawasan. Hasil diskusi menunjukan, konsep yang dapat diterapkan yaitu pengunjung diarahkan untuk dapat mengganti biaya bibit mangrove kemudian 
pengelola langsung mengarahkan ke lokasi penanaman, dan menyiapakn papan nama yang berisikan keterangan jenis mangrove dan identitas wisatawan yang menanam. Bibit mangrove yang disiapkan yaitu jenis bakau ( $R$. mucronata) karena jenis ini tahan terhadap genangan air laut dan sangat cocok ditanam langsung di daerah pasang surut (Pranatha et al., 2015)

\section{Film Mangrove}

Salah satu fasilitas yang disiapkan oleh pengelola adalah informasi kawasan Mangrove Tanjung Batu dalam bentuk film pendek,. Tim pengabdian dan pengelola mendesain film dokumenter yang bersikan profil kawasan, sejarah kawasan, dan informasi umum tekait mangrove serta jenis-jenis mangrove dan satwa burung di kawasan Mangrove Tanjung Batu.

Konsep yang dibangun yaitu, pengunjung yang datang akan diarahkan ke pusat informasi, kemudian sebelum wisatwan melakukan perjalanan, akan diputarkan film pendek terkait mangrove. Hal ini bertujuan untuk memberikan gambaran pada wisatwan terkait kondisi mangrove di kawasan wista, dan mendukung pendidikan konservasi berbasis ekosistem mangrove bagi siswa sekolah dasar.

\section{Bersampan}

Tim abdimas kemudian merekomenadasikan kegiatan bersampan bagi pengunjung untuk dapat berkeliling pada kawasan mangrove. Kegiatan ini juga berfungsi memberikan informasi terkait nilai penting tanaman mangrove dalam melindungi dan mengendalikan kawasan pesisir. Pada saat melakukan kegiatan ini, pengunjung juga diperkenalkan dengan jenis-jenis mangrove di sekitar, yang dapat dikenalkan secara langsung oleh pemandu wisatawan yang telah disiapkan oleh pengelola.

\section{KESIMPULAN}

1. Hasil kegiatan pengabdian yang dilakukan menggambarkan potensi Flora di Tanjung Batu yaitu Rhizophora mucronate, Rhizophora stylosa dan Avicennia lanata. Sedangkan jenis burung yang terdapat di Kawasan ini yaitu Dara Laut, Walet, Elang Hitam, Burung Gereja, Raja Udang dan Cerek Asia

2. Kegiatan penataan Kawasan yang dilakukan oleh tim abdimas yaitu membuat papan informasi terkait jenis flora-fauna yang terdapat pada kawasan Mangrove Tanjung Batu dan pembuatan film yang berisi profil kawasan dan infromasi umum tekait mangrove.

3. Rekomendasi jenis aktifitas wisata edukasi yang dapat ditawarkan untuk kawasan Mangrove Tanjung Batu yaitu bird watching, penanaman mangrove, bersampan, dan pembuatan film mangrove.

\section{DAFTAR PUSTAKA}

Direktur Jenderal Planologi Kehutanan dan Tata Lingkungan. (2017). Petunjuk Teknis Inventarisasi Hutan Pada Kesatuan Pengelolaan Hutan Lindung (KPHL) dan Kesatuan Pengelolaan Hutan Produksi (KPHP). Direktorat Jenderal Planologi Kehutanan Dan Tata Lingkungan Kementerian Lingkungan Hidup Dan Kehutanan, Jakarta, P.1/PKTL/IPSDH/PLA.1/1/2017.

Fandeli, chafid. (2002). Perencanaan kepariwisataan Alam. Fakultas kehutanan Universitas Gadjah Mada.

Fandeli, chafid, \& Mukhlison. (2000). Pengusahaan Ekowisata. Fakultas kehutanan Universitas Gadjah Mada.

Lakiu, M. D., Langi, M. A., \& Hard N. Pollo. (2016). Potensi Avifauna Untuk Pengembangan Ekowisata Birdwacthing Di Desa Ekowisata Bahoi. Cocos, 7(2).

Medrizam, Pratiwi, S., \& Wardiyono. (2004). Wilayah Kritis Keanekaragaman Hayati Di 
Indonesia: Instrumen Penilaian dan Pemindaian Indikatif/Cepat Bagi Pengambil Kebijakan. 77.

Pranatha, I. M. A., Arthana, I. W., \& Utami, N. W. F. (2015). Perencanaan Lansekap Wisata Berbasis Edukasi Mangrove di Restoran Akame, Benoa. Jurnal Arsitektur Lansekap, 1(1), 31. https://doi.org/10.24843/jal.2015.v01.i01.p04

Sukara, G. N., Mulyani, Y. A., \& Muntasib, E. K. S. H. (2014). Potensi untuk pengembangan wisata birdwatching di pusat konservasi tumbuhan Kebun Raya Bogor. Buletin Kebun Raya, 17(1), 44-56.

Susilawati, K. I., Baliwati, Y. F., \& Madanijah, S. (2008). Keanekaragaman Hayati Hutan Kemasyarakatan Untuk Mendukung. 3(November), 212-216.

Welford, M. R., \& Anthony Barilla. (2014). Is neotropical conservation sold-short: Diminishing returns for birding suggest ecolodges could encourage longer stays. Journal for Nature Conservation, 21, 401405.

Wijaya, F. (2020). Perancangan Wisata Edukasi Mangrove Di Kab. Lamongan dengan Pendekatan New Organic Architecture. Universitas Islma Negeri (UIN) Maulana Malik Ibrahim. 